\title{
MASCULINIZATION OF A FEMALE FOETUS WITH OESTROGENIC EFFECT
}

\author{
BY
}

\author{
G. H. VALENTINE \\ From the St. Thomas Elgin General Hospital, St. Thomas, and the Department of Paediatrics, University of Western \\ Ontario, Canada
}

(RECEIVED FOR PUBLICATION MAY 20, 1959)

Masculinization of a female foetus by androgenic hormones produced by an arrhenoblastoma in the mother during pregnancy was described by Brentnall (1945). Masculinization and pseudohermaphroditism caused by the administration of 17-methyltestosterone to the mother during pregnancy was reported by Hayles and Nolan (1957), Grunwaldt and Bates (1957) and others.

Since Wilkins, Jones, Holman and Stempfel (1958) described masculinization of the female foetus attributed to the administration of progestins with androgenic activity, an increasing number of cases of non-adrenal pseudohermaphroditism are being recognized. Their paper reports 21 cases of nonadrenal masculinization of the external genitalia. In 15 cases the oral progestin 17-ethinyl-testosterone (ethisterone or anhydrohydroxyprogesterone) had been given, in two cases the mother had received intramuscular injections of progesterone, in one case the progesterone had been given together with oral methyltestosterone and in three cases no steroid had been administered.

Since the publication of their paper the number of cases observed by them or collected from colleagues' reports has risen to 60 . The mothers of 25 had received 17-ethinyltestosterone; the mothers of 28 had been given 17-ethinyl-19-nortestosterone (norethindrone, norlutin) (Wilkins, 1959).

The clinical picture resembles the more familiar pseudohermaphroditism of the adrenogenital syndrome. Phallic enlargement varies according to the degree of labio-scrotal fusion. Complete fusion and a penile urethra may occur, though the formation of a urogenital sinus or phallic enlargement alone is more usual. The baby is chromatin positive. The mother has been given a progestin early in the pregnancy, usually with the intention of preventing a miscarriage. There is no increase in the urinary 17-ketosteroids and no abnormality of the internal genitalia. The condition is not progressive once the baby has been removed from the influence of the administered progestin and, apart from surgical correction of the external abnormality, if necessary, for psychological, cosmetic or reproductive purposes, no treatment is required. The outlook for childbearing is good.

Our case is believed to be unique in that, although there was masculinization, there is also strong evidence of a potent oestrogenic effect.

\section{Case History}

After two miscarriages the mother was given by mouth the synthetic progestin steroid 17-ethinyl-19-nortestosterone (norlutin) from the time when she missed her first period. She received $5 \mathrm{mg}$. twice daily throughout the pregnancy except at the times when the first three periods were due when she was given $5 \mathrm{mg}$. four times daily. About the third month she noticed that her voice was becoming deep and she was seen by an otolaryngologist who found only some oedema of the vocal cords. The significance of the deepening of the voice was not appreciated at that time. She noticed also that the hair on her head appeared to grow more rapidly than formerly, but she noted no other abnormality. The delivery was normal at term.

The baby appeared superficially to be a normal female. She developed quite deep jaundice eight hours after birth, but no blood group incompatibility haemolytic disease could be demonstrated. The jaundice soon faded. At 5 days the baby had slight vaginal bleeding, but this was not considered very unusual. She made excellent progress. During the next few weeks the mother noticed a good deal of mucous vulval discharge which did not cause her any concern.

When 10 weeks old the child had vaginal bleeding lasting six days, and this prompted further investigation. The nipples were abnormally prominent and slightly pigmented and there was a small button of breast tissue beneath. The labia majora were large, slightly wrinkled and very slightly pigmented. The clitoris was very definitely enlarged with a small palpable corpus cavernosum and a small visible glans. The appearance was similar to that in the case illustrated by Hillman (1959). 
There was no posterior fusion at the fourchette and a vaginal orifice at the usual site was visible. The hymen was fleshy and redundant, overlying and partly obscuring the urethral opening. The appearance of the vulval lining was quite unusual for a baby of this age. There was a copious mucoid colourless discharge and the mucosa was obviously thickened and pale. These changes themselves suggested the possibility of an oestrogenic effect. The depth of the vagina was $1 \frac{3}{4}$ in. and a normal uterus could be felt per rectum. No ovarian tumour was palpated.

A buccal mucosal smear showed that the chromosomal pattern was that of a genetic female. Radiography showed that the bone age was normal for the chronological age. Two 24-hr. specimens of urine showed 17 -ketosteroid levels of 0.19 and $0.14 \mathrm{mg}$. A $48-\mathrm{hr}$. specimen was examined for gonadotrophic folliclestimulating hormone and, although conducted at the most sensitive level, no such hormone was detected. A vaginal smear was made by aspirating a small amount of the initially copious discharge from high in the vagina. This showed that $28 \%$ of the cells were cornified. This is a high index of cornification and is comparable to that found in a woman in the reproductive age. Although Wilkins et al. (1958) recommend that investigation should include radiography and endoscopic examination of the urogenital sinus or vagina and also laparotomy and gonadal biopsy, it was felt that the baby should simply be watched in spite of the unusually high cornification index.

The baby thrived normally. Examinations and vaginal smears were made at frequent intervals. The vulval mucosa became more obviously delicate over the next three months and the mucoid secretion more scanty so that the preparation of satisfactory smears became increasingly difficult. The cornification index is shown in Fig. 1 .

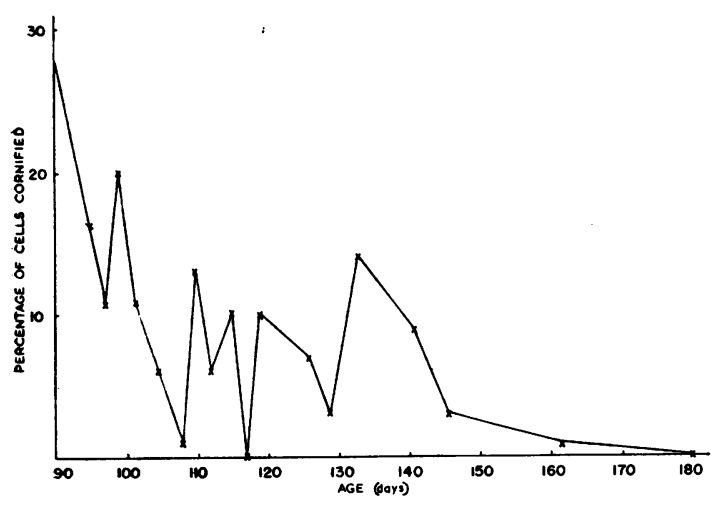

FIG. 1.-Vaginal smear cornification index.

Finally, the appearance of the vulva became normal, apart from the enlarged clitoris which did not change. There was no further bleeding. Along with the return toward normal of the vulval mucosa the nipple prominence and pigmentation and the slight breast enlargement disappeared, and by the age of 6 months the breasts appeared normal.

The mother's voice, though less deep than at the end of the pregnancy, is still rather husky.

\section{Discussion}

It now seems well established that certain of the synthetic progestins, and even progesterone itself, may have androgenic activity. In 15 of the cases described by Wilkins et al. (1958) the oral progestin 17-ethinyl-testosterone was incriminated. This steroid is said to have $7 \%$ of the androgenic activity of testosterone, as judged by its effect on the prostate and seminal vesicles of the castrated rat (Vollmer, 1958). The steroid in question in this case, 17ethinyl-19-nortestosterone, is stated by the same authority to possess $20 \%$ of the activity of testosterone, when judged by its effect on the prostate, and $113 \%$ of the activity of testosterone, when judged by its effect on the seminal vesicles of castrated rats. The androgenic activity of the steroid used in this case is thus considerable. Moreover it was administered from the time when the first menstrual period was missed and was continued throughout the pregnancy. It seems reasonably certain that the masculinization of this baby was due to the effect of the progestin used.

The oestrogenic effect as shown by the vaginal smears is not easy to explain. Its association with the masculinization can scarcely be coincidence. There was no reason to suspect that the baby had received oestrogens from vitamin drops, cosmetic preparations or the like. There was the possibility that a pituitary-activated temporary precocious puberty had occurred as a form of rebound overactivity of a gland depressed for a time by the steroid administered to the mother. That no follicle-stimulating hormone was detected in the urine does not vitiate this possibility. By the time that the estimation was made at 12 weeks of age the gonadotrophin level might have dropped a great deal. Even if present, the estimation might not have been of sufficient sensitivity to detect it. This possibility of pituitary over-activity certainly remains.

The possibility of an ovarian or even an adrenal oestrogen-producing tumour was considered but was rejected when the cornification index was seen to be falling and when no ovarian tumour could be palpated.

Most plausible of all is the hypothesis that part of the androgenic progestin administered to the mother became converted to an oestrogen. Oestrogens do not protect the foetus from the masculinization effect (Wilkins et al., 1958) whereas there is good evidence that androgens can be converted to oestrogens which 
result in cornification of the vagina (Steinach and Kun, 1937; Nathanson and Towne, 1939; Heard, Jellinck and O'Donnell, 1955).

If, as seems probable, such a conversion was responsible for the oestrogenic effect shown in this case, the question then arises: Did the conversion occur in the mother with transfer of both androgen and oestrogen to the baby, or was the conversion from androgen to oestrogen entirely in the baby? I do not think one can answer this. In any case it certainly seems that the source of oestrogen persisted in the baby for some months, but the storage of androgen or oestrogen (or both) seems unlikely.

Nevertheless it might have been quite possible for the developing foetal tissues, exposed as they were for nearly nine months to the administered progestin, to store sufficient for a diminishing effect to be shown for many weeks. Oestrogens, like bilirubin and a number of other substances, require conjugation before they can be removed as active agents (Kretchmer, 1959). Conjugation of this kind is known to be extremely ineffective in newborn infants. Failure of this conjugation mechanism might well have perpetuated the activity of the oestrogen. It is also possible that the early onset of jaundice, which raised the possibility of haemolytic disease, might have resulted from competition by the oestrogen with bilirubin for the conjugation pathway. Perhaps such competition for the glucuronideconjugating mechanism explains why sulfisoxazole
(Gantrisin), which also requires conjugation for its excretion, may cause hyperbilirubinaemia in the newborn premature baby.

\section{Summary}

A case of non-adrenal pseudohermaphroditism in a female newborn baby is described. In addition to the masculinization, an oestrogenic activity was demonstrated. The masculinization is attributed to the administration to the pregnant mother of an androgenic progestin. There is speculation as to the cause of the oestrogenic effect.

My thanks are due to Dr. J. Walters and Dr. Earl Plunkett, both of the University of Western Ontario and the Ontario Cancer Foundation. The former generously examined the many vaginal smears and the latter kindly arranged for the hormonal estimations in the Collip Laboratory. The help of both is gratefully acknowledged. Dr. Murray Barr kindly determined the chromosomal pattern. Dr. J. F. Curtis, of St. Thomas, referred the case to me.

\section{REFERENCES}

Brentnall, C. P. (1945). J. Obstet. Gynaec. Brit. Emp., 52, 235. Grunwaldt, E. and Bates, T. (1957). Pediatrics, 20, 503.

Hayles, A. B. and Nolan, R. B. (1957). Proc. Mayo Clin., 32, 41.

Heard, R. D. H., Jellinck, P. H. and O'Donnell, V. J. (1955). Endocrinology, 57, 200.

Hillman, D. A. (1959). Canad. med. Ass. J., 80, 200.

Kretchmer, N. (1959). Pediatrics, 23, 638.

Nathanson, I. T. and Towne, L. E. (1939). Endocrinology, 25, 754

Steinach, E. and Kun, H. (1937). Lancet, 2, 845.

Wilkins, L. (1959). Personal communication.

Wilkins, L., Jones, H. W. Holman, G. H. and Stempfel, R. S. (1958). J. clin. Endocr., 18, 559 .

Vollmer, E. P. Personal communication cited by Wilkins et al. (1958). 